\title{
A DOCÊNCIA ONTEM E HOJE ENTRE O SER AMADO E O SER TEMIDO: A QUESTÃO DA AUTORIDADE
}

\author{
LA ENSEÑANZA DE AYER Y DE HOY ENTRE EL SER AMADO Y SER \\ TEMIDO: LA CUESTIÓN DE LA AUTORIDAD
}

\author{
TEACHING YESTERDAY AND TODAY BETWEEN BEING LOVED AND \\ BEING FEARED: THE PROBLEM OF AUTHORITY
}

\author{
Elvis Rezende MESSIAS ${ }^{1}$ \\ André Luiz Sena MARIANO ${ }^{2}$
}

RESUMO: O presente artigo propõe-se a levantar reflexões acerca da questão da autoridade inerente à atividade docente. Tal reflexão parte de referenciais teóricos de correntes e períodos históricos distintos, sem a preocupação necessária de abordá-los em uma sucessão linear. $\mathrm{O}$ enfoque se dá às dificuldades enfrentadas na tensão entre o ser amado e o ser temido e na difícil decisão a que, frequentemente, os professores, líderes em sala de aula, se sentem pressionados a tomar entre uma coisa e outra. Questiona-se, entretanto, a necessidade real desta possível escolha, com o objetivo geral de trazer à luz a importância de se pensar equilibradamente a autoridade como serviço à alteridade e à autonomia verdadeiras.

PALAVRAS-CHAVE: Docência. Autoridade. Alteridade.

RESUMEN: En este artículo se reflexiona sobre la cuestión de la autoridad inherente a la enseñanza. Su reflexión se basa en los marcos teóricos de diferentes períodos históricos y actuales, sin la suficiente preocupación para acercarse a ellos en una sucesión lineal. El foco del análisis está dirigido a las dificultades que enfrentan en la tensión entre ser amado y ser temido y decisión difícil que a menudo los maestros, líderes en el aula, se sienten presionados a tomar entre una cosa y otra. Es cuestionable, sin embargo, la necesidad real de esta elección, con el objetivo general de sacar a la luz la importancia de la reflexión equilibrada de la autoridad como un servicio a la alteridad y autonomía verdaderas.

PALAVRAS CLAVE: Enseñanza. Autoridad. Alteridad.

\footnotetext{
1 Mestre em Educação pela Universidade Federal de Alfenas (UNIFAL/MG). Professor do Instituto Filosófico São José (Diocese da Campanha/MG), da SEE/MG e do COOPEC/TC. E-mail: elvisccae@oi.com.br

2 Professor Adjunto do Instituto de Ciências Humanas e Letras e do Programa de Pós-Graduação em Educação da Universidade Federal de Alfenas (UNIFAL/MG). Doutor em Educação pela Universidade Federal de São Carlos (UFSCar). E-mail: senamariano@gmail.com
} 
ABSTRACT: This article aims to reflect on the problem of authority inherent in the teaching activity. The reflection of theoretical reference currents and different historical periods, in a nonlinear approach. The focus is in the tension between being loved and being feared and often difficult to decide between them. However, it questioned the real need for this choice, aiming to think the authority as a service to the true otherness and autonomy.

KEYWORDS: Teaching. Authority. Otherness.

\section{Introdução}

O problema da autoridade em ambiente escolar, ligado à formação de professores, às construções curriculares e, especialmente, à prática pedagógica em sala de aula é algo que demanda reflexão séria e compromissada por parte daqueles que se dispõem à pesquisa em educação. Inserido na preocupação com esse tipo de reflexão, o presente artigo levanta questões, em sua introdução, sobre o problema da autoridade na perspectiva maquiaveliana de discussão sobre o poder. Inspirado por essas discussões iniciais, na primeira parte é feita a aproximação da questão da autoridade com o contexto da prática docente, restringindo o tema à dimensão educacional e seus desafios para, posteriormente, na segunda parte, estabelecer reflexões acerca da relação entre autoridade, alteridade e autonomia, a fim de serem feitas contribuições para pensar a problemática do artigo como um serviço à vida e à liberdade do sujeito.

Pelo menos desde Maquiavel (1469-1527), filósofo italiano natural de Florença, a problemática da liderança é posta em análise muito seriamente, em sua ligação especial com a luta concreta pela conquista e pela manutenção do poder político. $\mathrm{O}$ trânsito entre o ser amado e o ser temido não é simples de ser feito nem identificado, uma vez que existe uma oscilação entre uma realidade e outra por conta da ambiência afortunada a que o filósofo florentino caracteriza a dimensão cosmológica da vida. Um líder que não se atenta a essa dinâmica está fadado a ser surpreendido pela fortuna ${ }^{3}$, em decorrência de sua falta de flexibilidade e virtude para lidar com suas intempéries.

A atividade do governante - caso em análise por Maquiavel em $O$ príncipe - é desafiante, pois ele precisa se atentar frequentemente para os imprevistos que podem assolar seu poder a qualquer momento e se capacitar a resolvê-los com a máxima

${ }^{3}$ Conceito importante da filosofia maquiaveliana, cuja breve significação será apresentada de modo contextualizado mais à frente. 
objetividade. Para tanto, é fundamental se preparar técnica e teoricamente para o exercício de sua função, além de procurar conhecimento da natureza humana, a fim de não se deixar levar por qualquer pressão externa de cunho afetivo e desequilibrado. $O$ conselho de Maquiavel é que o governante faça um cálculo negativo dos súditos, se preparando para receber com firmeza suas reclamações e lidar com suas tendências egoístas, evitando afetações excessivas e subjetivismos, sem muita preocupação em ser amado ou temido - embora dê primazia à segunda -, uma vez que o que importa é o cumprimento efetivo de sua função, qual seja: manter a ordem social, o bem comum e, consequentemente, o próprio poder.

\begin{abstract}
Nasce daí uma questão: é melhor ser amado do que temido, ou o contrário. Responde-se que se quer ser tanto um quanto o outro. Mas como é difícil reuni-los, é muito mais seguro ser temido do que

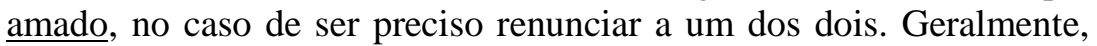
pode-se dizer que os homens são ingratos, volúveis, mentirosos, traiçoeiros, covardes, ávidos por dinheiro. Se lhes fazes o bem, todos estão contigo. Oferecem-te o sangue, as coisas, a vida, os filhos, como disse antes, quando a necessidade está longe de ti. Mas quando a necessidade chega perto, eles se rebelam. E o príncipe que havia se baseado completamente nas palavras deles, se não tiver outras defesas, arruína-se. [...] O amor é mantido por um vínculo de obrigação, que os homens, sendo malvados, rompem quando melhor lhes servir. Mas o temor é mantido pelo medo de ser punido, o que nunca termina. Todavia, o príncipe deve se fazer temer de um modo que, se não conquista o amor, evita o ódio (MAQUIAVEL, 2007, p. 84-85. Grifos nossos).
\end{abstract}

Maquiavel, neste sentido, propõe-se a uma visão realista da política, buscando as formas e condições de tomada e manutenção ${ }^{4}$ do poder. Seu pensamento é caracterizado como "laicização do político", , pois desloca a estrutura metafísica para a realista, evidenciando a nova visão de história inaugurada no humanismo, marcadamente horizontal na sucessão dos fatos - contraponto à verticalidade medieval. Ora, uma prova concreta dessa visão maquiaveliana, conforme já acenado, é o seu conceito de "virtú", que é a virtude, não como qualidade moral individual quase metafísica, mas a virtude

\footnotetext{
${ }^{4}$ A ideia de "manutenção" do poder não se limita a uma simples conquista do poder pelo poder, mas se refere às ações concretas necessárias para que este seja mantido e o governante tenha condições efetivas de exercer seu governo. Não se justificam quaisquer atos para atingir determinados fins irrefletidamente, mas que as situações efetivas determinarão quais meios serão melhores para bem resolver os problemas específicos que se apresentarem.

${ }^{5}$ Vale notar que "o político", para Maquiavel designa o ser político mesmo, ou seja, a forma de pensar as relações humanas na sociedade, as noções ideais da estrutura das relações que se dão no Estado, enquanto ambiente cívico; a natureza da política. Por outro lado, "a política" é a atividade mesma do político, sendo essa a parte a que Maquiavel se dedica em seus estudos.
} 
pensada em seu aspecto socialmente mais abrangente, como capacidade de flexibilidade moral, a partir da adequação aos tempos. Ou seja, diante da "fortuna", que é a inconstância e implacabilidade dos tempos, o governante deve se desprender de uma moralidade estanque e, flexivelmente, se adequar às mudanças e às sortes dos tempos para manter-se no poder, dissociando moral/ética e política, vistas como ramos distintos, sendo a política um ramo onde as escolhas são de natureza muito mais complexa e menos sentimental do que no campo moral.

É interessante notar que, nesta luta objetiva pela manutenção do poder e da ordem, o governante deve evitar uma prática muito cordial. Fato é que a preocupação entre ser amado e/ou ser temido se faz presente no imaginário de todas as pessoas, mas, segundo a problemática política analisada por Maquiavel, tal preocupação é secundária, sendo, inclusive, preferível ser temido que amado, conforme citado, porque o temor não é tão efêmero quanto o amor. Ou seja, pelo temor é mais segura a manutenção do respeito por si, embora o ser temido não deva nunca ser odiado, pois o ódio move as pessoas furiosamente umas contra as outras e isso é extremamente perigoso para a manutenção objetiva do poder. Ademais, vale notar que Maquiavel inúmeras vezes na sua obra aponta para uma preocupação com atos que prejudiquem o povo, a partir da qual o manter-se no poder parece possuir certa identificação fundamental com a ideia de 'bem governar'.

Recomenda, por exemplo, que "um príncipe deve gastar pouco para não ser obrigado a roubar seus súditos", mesmo que isso lhe valha a fama de miserável, o que é sempre preferível a ser odiado pela população por cobrar pesados impostos. Aconselha também que é melhor ser considerado cruel, pois a tolerância é capaz de gerar "desordens, das quais podem nascer assassínios ou rapinagem", que "prejudicam o povo". Além disso, afirma que o governante, para não ser derrubado, deve ser estimado e que, para isso, é preciso assegurar e estimular o livre exercício das atividades dos súditos (ABRÃO, 2004, p. 158).

Como se nota, o tema da autoridade e da liderança é evidenciado como algo extremamente melindroso, cobrando-se do seu detentor muita flexibilidade moral, além de um arcabouço teórico considerável para lidar com máxima sabedoria diante da realidade, tal como ela se apresenta, muito mais complexa e dinâmica que os meros e diversos planos de ação social. 


\section{Autoridade e docência}

A dimensão educacional destas reflexões propedêuticas se nos apresenta digna de reflexão, pois, muito frequentemente, o professor em sua atividade docente se vê extremamente envolvido no joguete ser amado/temido/odiado, seja pelos alunos, seja pelos demais professores, supervisão, direção, inspeção, comunidade escolar e tudo mais que se ajunte ao complexo pedagógico. $\mathrm{O}$ espaço educacional é uma arena de afetividade, onde histórias e visões de mundo se chocam, e a maturidade afetiva é tão necessária quanto urgente, e sua falta um perigo. Em especial no Brasil, cuja dimensão cordial é presença radicalmente marcante em todas as esferas públicas, segundo Sérgio Buarque de Holanda, a problemática amor/temor/ódio é perene, em que elementos da experiência afetiva cotidiana se sobrepõem a teorias e objetividades. O terreno relacional brasileiro é especialmente marcado por ventos de oposição e incompatibilidade entre instâncias subjetivas e objetivas, familiares e estatais, privadas e públicas, de tal forma que entre leis gerais e leis particulares sempre houve certa tensão, e a confusão entre afetividade e sentimentalismo, assim como entre objetividade e subjetividade, é um equívoco hermenêutico que, não raramente, gera discussões e incompreensões preocupantes. A objetividade, entretanto, não é posta em detrimento da subjetividade que, por sua vez, junto com a afetividade e a individualidade, não se deságua, necessariamente, no subjetivismo nem no individualismo - entendidos aqui, de modo geral, como valorização exagerada e pouco refletida da dimensão subjetiva e individual.

No Brasil, pode dizer-se que só excepcionalmente tivemos um sistema administrativo e um corpo de funcionários puramente dedicados a interesses objetivos e fundados nesses interesses. Ao contrário, é possível acompanhar, ao longo de nossa história, o predomínio constante das vontades particulares que encontram seu ambiente próprio em círculos fechados e pouco acessíveis a uma ordenação impessoal. Dentre esses círculos, foi sem dúvida o da família aquele que se exprimiu com mais força e desenvoltura em nossa sociedade. E um dos efeitos decisivos da supremacia incontestável, absorvente, do núcleo familiar - a esfera, por excelência, dos chamados "contatos primários", dos laços de sangue e de coração - está em que as relações que se criam na vida doméstica sempre forneceram o modelo obrigatório de qualquer composição social entre nós. Isso ocorre mesmo onde as instituições democráticas, fundadas em princípios neutros e abstratos, pretendem assentar a sociedade em normas antiparticularistas (HOLANDA, 2013, p. 146). 
A tentativa de fazer do Estado uma substituição à altura da Família, porém com traços de impessoalidade mais acentuados, parece que nunca vingou no Brasil. Na educação, por sua vez, isso é gritante quando se percebe as dificuldades que um professor "menos afetivo" enfrenta para "conquistar o coração" dos alunos e o quanto ele sofre com os "modelos pedagógicos mais lúdicos". Quantas vezes é preciso, além da função de professor, assumir o papel de animador de auditório, de artista eclético e de palhaço de circo para ser aceito, amado e respeitado. Que tipo de aceitação é essa? Que tipo de amor é esse? Que tipo de respeito é esse? Por outro lado, inúmeras vezes, por medo de ser temido e odiado, e pelos estímulos pedagógico-histórico-culturais constantes que recebe para ser um professor "bonzinho", o próprio docente vive submerso em uma atmosfera exacerbada de carência, extremamente necessitado de abraços, carinhos e elogios para se acreditar um "bom profissional", perpetuando-se a dificuldade de estabelecer coerentemente a fronteira entre o escolar, o profissional e o pessoal.

Perigoso esse "fetichismo" e essa mercantilização do ensino, da educação, dos conteúdos, essa instrumentalização do conhecimento historicamente construído, confinado às esferas subjetivistas do presente. A cultura zapping, líquida ${ }^{6}$ e descartável da atualidade frequentemente ameaça tornar docentes e discentes reféns de estímulos sentimentalistas e individualistas, submetendo-os, em sua grande maioria, ao terror de não serem aceitos em suas individualidades. Se, de um lado, Maquiavel propõe uma ação social bastante objetiva, tendo em vista o bem comum e a manutenção do poder, ainda que isso custe a alcunha de um governante rude, por outro, vê-se uma contemporaneidade imersa em uma superficialidade de perspectiva, em que a noção de "bem estar" assumiu dimensões de prazer rápido, momentâneo e imediato.

Em se tratando de Brasil, há quem diga que a grande contribuição do brasileiro para o mundo seja justamente a noção de cordialidade, de hospitalidade generosa, "de fundo emotivo extremamente rico e transbordante" (HOLANDA, 2013, p. 147). Se os japoneses e outros povos se gabam de sua polidez ritualística e quase fria, os brasileiros parecem se orgulhar da sua cordialidade emotiva e calorosa. Segundo Sérgio Buarque de Holanda (2013, p. 147), o povo brasileiro procura distância dessa noção ritualista da vida, sendo justamente "a forma natural e viva que se converteu em fórmula" por aqui.

6 Tomamos este termo emprestado do sociólogo contemporâneo polonês Zigmunt Bauman, termo consagrado e amplamente trabalhado em várias de suas renomadas obras, tais como Modernidade Líquida, Medo Líquido, Amor Líquido, Sociedade Individualizada, Ética na Pós-Modernidade, entre outros.

RIAEE - Revista Ibero-Americana de Estudos em Educação, v. 12, n. 2, p. 815-831, 2017. 
A vida em sociedade, segundo o espírito brasileiro, possui essas características emotivas para, de certo modo, tornar a própria vida mais leve, livre do peso excessivo de ter que apoiar-se em si mesmo, conforme propunha o "espírito desfamiliarizado" do capitalismo, em todas as circunstâncias da existência.

O desconhecimento de qualquer forma de convívio que não seja ditada por uma ética de fundo emotivo representa um aspecto da vida brasileira que raros estrangeiros chegam a penetrar com facilidade. E é tão característica, entre nós, essa maneira de ser, que não desaparece sequer nos tipos de atividade que devem alimentar-se normalmente da concorrência. Um negociante da Filadélfia manifestou certa vez a André Siegfried seu espanto ao verificar que, no Brasil como na Argentina, para conquistar um freguês tinha necessidade de fazer dele um amigo. (HOLANDA, 2013, p. 148-149).

Entende-se, porém, que o conceito de "cordial” em Holanda não significa benignidade, bondade, afabilidade. O "homem cordial" é aquele que age pelo coração (cor, cordis, em latim), pelo impulso sentimental, podendo ser ao mesmo tempo amável e hostil, carinhoso e violento. A proximidade dos contrários é uma marca especial do homem brasileiro e da sociedade brasileira, segundo este autor, de tal forma que, por aqui, a doçura e a raiva são tão distantes e tão próximas quanto o Leblon e a Rocinha, o que afeta a noção de autoridade e do princípio da hierarquia que, para Holanda, "nunca chegou a importar de modo cabal entre nós" (2013, p. 35). E, talvez por isso, esses conceitos sejam tão mal compreendidos. Inclusive, o sociólogo brasileiro utiliza justamente essa dimensão contrária como metodologia especial de Raízes do Brasil, atendo-se à dimensão dinâmica das mais diversas paridades, tais como trabalho e aventura, público e privado, semeador e ladrilhador, campo e zona urbana, família e Estado, especialmente se tratando de um país de colonização Ibérica com profunda oscilação entre desordem e rigidez. Difícil aceitar como válidos, deste modo, aqueles discursos saudosistas que falam de um passado mais justo, sério e ordenado, uma vez que as instituições e a coesão social nunca foram, ao que indica, muito firmes no Brasil.

A falta de coesão em nossa vida social não representa, assim, um fenômeno moderno. E é por isso que erra profundamente aqueles que imaginam na volta à tradição, a certa tradição, a única defesa possível contra nossa desordem. Os mandamentos e as ordenações que elaboraram esses eruditos são, em verdade, criações engenhosas do espírito, destacadas do mundo e contrárias a ele. Nossa anarquia, nossa incapacidade de organização sólida não representam, a seu ver, mais do que uma ausência da única ordem que lhes parece necessária 
e eficaz. Se a considerarmos bem, a hierarquia que exaltam é que precisa de tal anarquia para se justificar e ganhar prestígio (HOLANDA, 2013, p. 33).

De fato, a experiência de ser tratado dignamente é insubstituível e absolutamente necessária, pressupondo certa dose de pessoalidade. Entretanto, essa pessoalidade não abre mão de manter as diferenças e os devidos respeitos hierárquicos. Há, de fato, uma diferenciação ontológica entre docentes e discentes, em decorrência das experiências e trajetórias trilhadas por cada ser em seus contextos vitais. Se o professor, por exemplo, se comportar igual ao aluno, não será um bom referencial para este e terá, consequentemente, bastante dificuldade para educá-lo e convencê-lo a se comportar de modo mais maduro e adulto. Isso não nos leva a concluir, por outro lado, que o ser adulto significa aqui uma antítese absoluta ao ser adolescente. Ao contrário, pressupõe, aristotelicamente falando, o desenvolvimento de potencialidades e estágios diferentes de compreensão da vida e do mundo que não se resumem atreladamente ao modo de ser um do outro. Tratar o estudante como estudante é fundamental e um sinal de respeito pela sua atual condição, procurando conhecer melhor a sua natureza e suas gradações específicas, como o tratar a criança como criança proposto por Rousseau no Emílio. Respeito maior, porém, pela atual condição do estudante é o professor não se encerrar acriticamente no mesmo estágio que aquele, sob o intuito ilusório de fazer-se melhor entender e para ser sentimentalmente mais "bem aceito". Saber lidar com a própria autoridade é um desafio longínquo, conforme já havia acenado Maquiavel.

Em Palavras e sinais, na parte intitulada Tabus que pairam sobre a profissão de ensinar, o filósofo alemão Theodor Adorno já havia alertado para o fato de quanto os professores que correspondem ao "ideal de homem mundano, os que jogam futebol ou os bons de copo, gozam de tanta preferência entre os alunos" (1995, p. 96). Muitos docentes, inclusive, conforme já apontado, recorrem a isso para suprirem seus vazios psicossociais, com toda a carga de necessidade de aceitação, amor e respeito que eles acarretam. Quantas vezes, educação e vida parecem habitar horizontes absolutamente distintos, como se o que é refletido no ambiente escolar estivesse em uma atmosfera muito distante da realidade vital dos estudantes e mesmo da própria vida do professor que, por sua vez, é visto como um representante de um papel, cujas vestimentas são abandonadas passado o "espetáculo" da sala de aula e que não servem para "realidade" da vida efetiva. Dessa alienação e dualidade social que, muitas vezes, não permite que a pessoa tenha contato esclarecido consigo mesma, dois problemas educacionais se impõem: o problema da carência, criando a necessidade de autoafirmação pela 
aprovação alheia, que pode levar o professor a se infantilizar em sua atividade; e o problema da indiferença, que pode levar o professor a não enxergar o aluno, o que ele sente e as suas reais demandas como pessoa biológica, histórica e socialmente situada. Aliás, quantas vezes a dimensão libertadora da educação se perde em atitudes opressivas de picuinhas entre professores, que buscam espaço e reconhecimento à custa do insucesso de outros colegas, de fofocas, de apropriação indevida das ideias e projetos alheios, de calúnias e falso testemunho, fazendo do ambiente escolar uma arena não só de afetividades, mas de uma verdadeira guerra egocêntrica, cujo império soberano é o da desconfiança e o da inveja, a partir do qual o estudante é frequentemente o último realmente a ser considerado. Evidente despreparo técnico e humano. E, nesta perspectiva, as pessoas se tornam reféns de si mesmas.

Bastante ilustrativa a anedota do filósofo francês Michel de Montaigne a seguir, extraída do seu ensaio Dos livros:

Observa-se igualmente que os palhaços que exercem sua profissão com talento tiram todo partido possível de sua arte, mesmo quando vestidos com seus trajes cotidianos, enquanto que os aprendizes, de menos competência, precisam enfarinhar a cara, mascarar-se, gesticular, e fazer caretas para nos obrigar a rir (MONTAIGNE, 1987, p. 194).

Deste modo, percebe-se a problemática da liderança e da autoridade como, de fato, central para se pensar a atividade docente, esse tipo de poder carregado de responsabilidades humanísticas e desafios sociais. Montaigne, por exemplo, embora não tenha produzido uma obra estritamente pedagógica, muito valorizou um modelo de educação preocupado com o desenvolvimento integral do estudante, além de ter sido uma pessoa extremamente grata ao seu pai por ter lhe dado preceptores que tinham certa docilidade e benevolência, não afeitos à violência nem à exagerada autoridade. Vejamos a postura montaigneana no excerto a seguir, extraído do seu ensaio intitulado $D a$ Educação das Crianças:

Seja como for, a essa educação deve proceder-se com firmeza e brandura, e não como é de praxe, pois, como o fazem atualmente, em lugar de interessarem os jovens nas letras, desgostam-nos pela tolice e crueldade. Deixem-se de lado a violência e a força: nada a meu ver abastarda mais e mais embrutece uma natureza generosa. Se quereis que o jovem tema a vergonha e o castigo não o calejeis nele (MONTAIGNE, 1987, p. 84). 
E acrescenta, ironicamente, em seguida:

A disciplina rigorosa da maior parte de nossos colégios sempre me desagradou. [...] Ide ver esses colégios nas horas de estudo: só ouvireis gritos de crianças martirizadas e de mestres furibundos. Linda maneira de acordar o interesse pelas lições nessas almas tenras e tímidas, essa de ministrá-las carrancudo e de chicote nas mãos! Que método iníquo e pernicioso! E observa muito bem Quintiliano que uma autoridade que se exerce de modo tão tirânico comporta as mais nefastas consequências, em particular pelos castigos (idem).

A dimensão intersubjetiva e a questão da autoridade, como se vê, são uma constante na relação educacional, que cobra dos agentes escolares e acadêmicos um compromisso real com o desenvolvimento humano em sua totalidade, evitando-se totalitarismos e cosmovisões únicas. O conceito de autoridade em Educação é extremamente complexo e, segundo Winch e Gingell (2015, p. 25), “quase sempre se divide em dois tipos: estar com a autoridade [...] e ser uma autoridade. Estar com a autoridade significa ter o direito e estar autorizado a fazer com que suas vontades sejam atendidas" e, completa dizendo, que "ser uma autoridade é possuir conhecimento no qual se pode confiar" (WINCH; GINGELL, 2015, p. 25). Os mesmos autores trabalham que, embora a tradição atribuísse os dois sentidos de autoridade aos educadores, tal conceito vem sendo questionado, especialmente pelos "educadores progressistas e centrados nas crianças", com grande destaque à filosofia da educação de Rousseau, evidenciando que a necessidade perene de uma harmonização entre a atividade docente e a questão da autoridade é extremamente urgente.

\section{Autoridade, alteridade e autonomia}

O desafio imenso que se apresenta a partir disso é compreender a autoridade como serviço, como um ministério a favor da libertação humana, da autonomia, da emancipação, do melhor da natureza humana ainda por vir, mas também do melhor já conquistado. O já citado Adorno, em outra obra sua, em diálogo com o educador alemão Helmutt Becker, intitulada Educação e emancipação, estabelece uma relação intrínseca entre autoridade, alteridade e autonomia, enfatizando que o significado do primeiro conceito pode ser compreendido de formas diferentes a partir do contexto social em que se apresenta, possuindo uma essência psicossocial. As figuras de autoridade, desde a 
nossa infância, se caracterizariam como pontos de "confluência das categorias sociais, pedagógicas e psicológicas" (ADORNO, 2006, p. 176). Em se tratando especificamente de educação, o professor precisa ter consciência e clareza, completa Becker (apud ADORNO, 2006, p. 177), "quanto a que sua tarefa principal consiste em se tornar supérfluo", ou seja, sua autoridade não consiste em aprisionar e silenciar ${ }^{7}$ autoritariamente mentes e pessoas, mas em criar espaços para que o seu aluno tenha condições de sempre e cada vez melhor viver independentemente, sem a tutela externa do seu mestre. A propósito, o pensamento humano é essencialmente dialógico, e não "monológico".

\begin{abstract}
O modo pelo qual - falando psicologicamente - nos convertemos em um ser humano autônomo, e portanto emancipado, não reside simplesmente no protesto contra qualquer tipo de autoridade. Investigações empíricas [...] revelaram justamente o contrário, ou seja, que as crianças chamadas comportadas tornaram-se pessoas autônomas e com opiniões próprias antes das crianças refratárias, que, uma vez adultas, imediatamente se reúnem com seus professores nas mesas dos bares, brandindo os mesmos discursos. É o processo - que Freud denominou como desenvolvimento normal - pelo qual as crianças em geral se identificam com uma figura de pai, portanto, com uma autoridade, interiorizando-a, apropriando-a, para então ficar sabendo, por um processo sempre muito doloroso e marcante, que o pai, a figura paterna, não corresponde ao eu ideal que aprenderam dele, libertando assim do mesmo e tornando-se, precisamente por essa via, pessoas emancipadas (ADORNO, 2006, p. 177).
\end{abstract}

Face positiva esta acerca da autoridade, amplamente necessária e humanizada, a que o professor, ao seu modo, não pode renunciar, na missão educacional em toda a sua dimensão libertadora. Erro, porém, a se evitar, é a absolutização deste papel, a fím de que não se destine à geração de um efeito colateral tirânico, não endossado pelo autor acima citado, e que completa seu raciocínio com muita propriedade e atualidade:

Penso que o momento da autoridade seja pressuposto como um momento genético pelo processo de emancipação. Mas de maneira alguma isto deve possibilitar o mau uso de glorificar e conservar esta etapa, e quando isto ocorre os resultados não serão apenas mutilações psicológicas, mas justamente aqueles fenômenos do estado de menoridade, no sentido da idiotia sintética que hoje constatamos em todos os cantos e paragens (ADORNO, 2006, p. 177).

${ }^{7}$ Sobre essa dimensão do silenciar, indicamos a leitura complementar da seguinte obra Ferrarezi Jr., Pedagogia do silenciamento: a escola e o ensino de língua materna. 
Impõe-se, daí, a necessidade de o professor ser um especialista em humanidades, com uma atividade pedagógica fortemente acompanhada de uma boa dose de firmeza de si; a necessidade do despertar da própria consciência acerca dos mecanismos de enganação, de manipulação e de alienação a que ele e os estudantes que estão sob sua responsabilidade são constantemente ameaçados, especialmente quando esses mecanismos são encontráveis no interior da própria instituição educacional. Essa especialização em humanidades poderá evitar o desprazer de ter que encontrar e conviver com docentes que se gabam de seus desmandos e desrespeitos com seus alunos e colegas de profissão, que se vangloriam de corrigir provas e fechar notas e diários atrasados em sala de aula, sobrecarregando os discentes com exercícios e atividades nada pedagógicas, cujo único intuito é dar um jeito de o tempo passar mais rápido com o falso desencargo de consciência de não tê-los deixado à toa.

O pathos da escola - hoje sua seriedade moral - nas presentes circunstâncias, reside em que, somente ela, se é consciente da situação, é capaz de trabalhar imediatamente pela desbarbarização da humanidade. Por barbárie [entende-se]: o preconceito delirante, a repressão, o genocídio e a tortura; aqui não há lugar para dúvidas. Opor-se a isso, tal como se nos oferece o mundo de hoje, onde ao menos não é possível vislumbrar nenhuma outra possibilidade de mais amplo alcance, compete antes de mais nada à escola. (ADORNO, 1995, p.103. Grifos nossos).

Até mesmo a educação jesuítica dos primórdios da Idade Moderna na Europa e do período colonial brasileiro, ao contrário do que possa pensar o senso comum, estava extremamente atenta à complexidade da dimensão da autoridade na docência. Segundo Faria (2010, p. 64), intensamente preocupados em "formar o homem virtuoso" e corrigir a natureza humana, os jesuítas, por meio das Constituições, dos Exercícios espirituais e do Ratio Studiorum, sempre trataram com muita seriedade a educação em todas as suas dimensões, de tal modo que "o ofício do ensino é, pois, a 'menina-dos-olhos' da Companhia" (FARIA, 2010, p. 70). Ainda que a disciplina, a ascese e a vigilância sobre si fossem fundamentais para que o aluno aprendesse a discernir os movimentos do próprio coração, um verdadeiro "método de santificação pessoal adquirido mediante a disciplina prescrita nos Exercícios espirituais" (p. 64), isso não justificaria atitudes amplamente rudes, cobrando-se dos agentes educacionais uma verdadeira e sutil sabedoria no uso da própria autoridade. Sobre a atividade do reitor, por exemplo, 
autoridade superior dos Colégios jesuítas, é importante ressaltar o seguinte excerto ilustrativo:

\begin{abstract}
Sobre as qualidades que se requeria ao reitor, o texto ressalta como não poderia deixar de ser, a importância das virtudes cristãs. Recomendava-se, assim, o exemplo, a edificação, a mortificação, que fosse especialmente provado na obediência e humildade; que fosse discreto e apto para o governo; que soubesse mesclar a severidade, a seu tempo, com a benignidade; que fosse cuidadoso e letrado; e, finalmente, que fosse alguém em quem se pudesse confiar e a quem se pudesse comunicar seguramente a autoridade do governo de um colégio. É, sem dúvida, interessante a referência à boa administração como qualidade para ocupar o cargo de reitor (FARIA, 2010, p. 75).
\end{abstract}

Com uma dinâmica parecida, o desenvolvimento da filosofia na Grécia também esteve o tempo todo articulado com uma espécie de Pedagogia, com um eixo transversal marcadamente ético e político. Ou seja, era extremamente considerada a necessidade de se desbravar a capacidade de conhecimento (Filosofia) para uma sólida educação dos indivíduos (Pedagogia) ao longo de toda sua existência social (Política), a fim de que vivessem bem em sociedade (Ética e Moral). Uma educação atenta aos aspectos disciplinares do indivíduo/cidadão, devidamente dosada entre rigidez e humanismo. Diante disso, vários nomes e grupos se destacaram e a reflexão filosófica amadureceu, especialmente, com o pensamento socrático, platônico e aristotélico.

Entre alunos e professores há, de fato, certa desigualdade, uma desigualdade que é real, mas que não é ruim. As pessoas socialmente possuem mais conhecimentos que outras em determinadas áreas e é, inclusive, quase sempre muito prazeroso poder beber de suas fontes intelectuais - quando elas estão preparadas para tanto - e formar o próprio ser a partir desta diferenciação ontológica. Isso, porém, não deve se tornar um meio de exploração alheia por meio da cultura, baseados numa pseudoautoridade que exclui ou justifica imposições hermenêuticas, conceituais, enfim, educacionais. Como bem disse Raymond Williams, "ninguém pode erguer o padrão cultural de ninguém. O máximo que pode ser feito é transmitir habilidades que não são pessoais, e sim uma propriedade humana geral” (WILLIAMS, 2011, p. 343). As escolhas, ao final, são de cada pessoa e, como já exortava o velho Sócrates, é diante do imenso mundo do não saber que, portanto, a nossa humana semelhança mais se revela. As pessoas, quando idealizadas absolutamente, são mortas antes mesmo de surgirem efetivamente no mundo. E a escola deve cuidar para que não se preste a este tipo de (des)serviço. 
Portanto, não se justificam atitudes tirânicas, especialmente em se tratando de educação. Inclusive, é sempre bom atentar quanto à perigosa proximidade que existe entre emancipação e tirania. Emancipação e tirania caminham muito proximamente. Educação e alienação também. Aliás, quantas vezes as escolas ensinam muito mais a obedecer do que a pensar?! Sendo assim, deve a autoridade ser pensada e se estabelecer como meio eficaz para que a vida dos outros seja algo colocado sempre mais nas mãos desses outros, a fim de que cada pessoa faça de sua história uma obra própria. Afinal, como alertou Montaigne, "o que temos de mais caro é a vida: e esta consiste em movimento e ação" (MONTAIGNE, 1987, p. 182).

\section{Considerações finais}

Todas as reflexões do presente artigo procuraram elucidar brevemente como a docência, em seu desenrolar histórico, esteve e está envolta aos processos de autoridade em sua relação com a dimensão da alteridade e da autonomia. O desenvolvimento de tais reflexões remeteu-se à necessidade educacional de um preparo constante para a decência da atividade docente, que deve constantemente colocar em xeque as próprias convicções e práticas, dando "lugar às dúvidas", e atentando-se ao vir-a-ser da vida e dos seus fatos, à inconclusão e à reticência da existência.

Para tanto, revelou-se pertinente o imperativo de que os profissionais da educação evitem toda espécie de dogmatismo, autoritarismo e engessamento da realidade, o que ajuda a melhor compreender a complexidade pedagógica do conceito de autoridade. Falando sobre "professores marcantes", por exemplo, Maria Eugênia Castanho (2001, p. 155) exalta a importante relação entre os aspectos profissionais e pessoais da prática docente, que formam "um todo indivisível e responsável por uma postura admirável como professor" (CASTANHO; CASTANHO, 2001, p. 155). Em suas pesquisas sobre as marcas deixadas por diversos docentes em seus alunos, os de maior destaque são descritos como "professores que 'amavam o que faziam', que 'valorizavam o aluno', que 'sabiam explicar muito bem a matéria', que 'motivavam as aulas', que eram 'seres humanos ímpares"”.

Que tipo de ser humano se quer para o mundo? Que tipo de sociedade se quer para ter o tipo de ser humano almejado? Que tipo de escola deseja-se para ter o tipo de sociedade que se quer, a fim de ter o tipo de ser humano almejado? Qual é o tipo de 
professor sonhado? Que tipo de estudante é idealizado? E por que são buscados esses determinados tipos de ser humano, de sociedade, de escola, de professor e de estudante? Quais valores motivam os seres humanos em seus desejos? E quais critérios são elencados para se fazer as escolhas que são feitas? Enfim, qual é o papel da educação? Interessante e lamentável perceber o quanto, no auge das crises de identidade e de autoridade dos docentes, essas questões tão fundamentais são as últimas que aparecem nas mais diversas reuniões de cunho pedagógico. Como é preocupante a paixão cada vez mais difundida por gabaritos e manuais didáticos, com receitas prontas e práticas, relegando as reflexões teóricas e as questões acima levantadas ao campo da contemplação privilegiada e, deste modo, completamente desnecessárias ao cotidiano escolar, "conversas apenas para gabinetes".

Urge compreender que a educação escolar e a dimensão de sua autoridade estão a serviço da vida, e não o contrário, devendo preparar o ser humano para que tenha condições de deliberar livremente e escolher criteriosamente o que for necessário para que tenha uma vida boa - tomando o devido cuidado com as tiranias autoritárias que insistem em definir o que seria esse "bem viver". "Saber reconhecer nossa ignorância é mesmo uma das mais belas e seguras garantias de que não carecemos da faculdade de julgar” (MONTAIGNE, 1987, p. 192). Mas, os responsáveis pela educação estão preparados para essa árdua, desafiante e bela missão? Fato é que há um processo de humanização do ser humano através das relações sociais - e a escola é um espaço peculiar de socialização -, mas é preciso que também haja um processo de humanização das próprias relações sociais para a possibilidade de uma humanização decente de ser humano. Grande desafio esse de saber lidar com a existência concreta do outro, bem como com o "vazio" que há nas pessoas, sem a pretensão de preenchê-los. É preciso que cada pessoa tenha condições críticas de dar à própria vida os significados que consciente e livremente deliberar.

Sempre perigosa, entretanto, é a tendência do Estado de querer educar somente para a heteronomia e não para a autonomia. Ora, refletir criticamente sobre os próprios atos e ter condições de exercitar o próprio julgamento é fundamental para se construir uma sociedade feita de pessoas que procuram ser justas e fazer bem ao bem comum; pessoas que têm a oportunidade de sempre e autonomamente se reavaliarem, podem estar mais aptas a viver em estado constante de honestidade intelectual, moral e existencial, o que também as possibilita a experimentar sadia alteridade. E não viver predatoriamente. Denuncia-se, consequentemente, um modelo estatal e educacional que, 
pouco ciente da dimensão humanística de sua autoridade, se presta mais à formação de predadores que de sujeitos, de competidores que de pessoas.

Fundamental, portanto, não é escolher entre ser amado ou ser temido, nem muito menos ser odiado. O que se impõe como desafio real ao docente é a maturidade para lidar com a própria autoridade frente à necessidade de uma educação que responda preparadamente ao exercício da alteridade e ao desenvolvimento da autonomia dos estudantes. Nesta perspectiva, é indispensável uma sólida e permanente formação profissional, que contemple efetivos domínios técnicos, conteudísticos, pedagógicos e didáticos, mas também a urgente formação humana, as imprescindíveis compreensões dos aspectos filosóficos, psicológicos, históricos e sociais da educação e daqueles que são, ao mesmo tempo, seus sujeitos e objetos. Tudo isso, com o intuito de que a docência responda mais preparada e positivamente à importância da flexibilidade virtuosa refletida por Maquiavel, à sabedoria sensível decorrente de uma releitura dos aspectos positivos da ideia de cordialidade instigada por Holanda, ao desenvolvimento educacional gradativo inspirado por Rousseau, à educação emancipadora proposta por Adorno e ao devido equilíbrio pedagógico entre a disciplina e a inteligência provocado por Montaigne. Afinal, autoridade sem alteridade torna mais frágil e mesmo improfícuo e tirano o espaço relacional da educação, e o ser amado e o ser temido se transformam em uma luta maniqueísta que negligencia a dimensão humana e política de uma prática educacional que deve estar preocupada com a autonomia e o desenvolvimento integral da pessoa e do bem comum.

\section{REFERÊNCIAS}

ABRÃO, Bernadette Siqueira. História da filosofia. São Paulo: Nova Cultural, 2004.

ADORNO, Theodor W. Educação e emancipação. 4.ed. Tradução de Wolfgang Leo Maar. Rio de Janeiro: Paz e Terra, 2006.

ADORNO, Theodor W. Palavras e sinais: modelos críticos 2. Tradução de Maria Helena Ruschel. Petrópolis: Vozes, 1995.

CASTANHO, Sérgio. CASTANHO, Maria Eugênia. (orgs.). Temas e textos em metodologia do Ensino Superior. Campinas: Papirus, 2001.

FARIA, Marcos Roberto de. Ética e educação jesuítica no século XVI: formar soldados para Cristo. Revista Filosofia Capital. Brasília: v. 5, n. 11, p. 62-76, 2010. ISSN: 19826613. 
FERRAREZI JR., Celso. Pedagogia do silenciamento: a escola e o ensino de língua materna. São Paulo: Parábola Editorial, 2014.

HOLANDA, Sérgio Buarque de, Raízes do Brasil. 26.ed. São Paulo: Companhia das Letras, 2013.

MAQUIAVEL, Nicolau. O príncipe. 18.ed. Tradução de Maria Lúcia Cumo. Rio de Janeiro: Paz e Terra, 2007.

MONTAIGNE, Michel de. Ensaios. V. I. Tradução de Sérgio Milliet. São Paulo: Nova Cultural, 1987. (Coleção Os Pensadores)

ROUSSEAU, Jean-Jacques. Emílio ou da educação. 2.ed. São Paulo: Difusão Europeia do Livro, 1973.

WILLIAMS, Raymond. Cultura e sociedade: de Coleridge a Orwell. Tradução de Vera Joscelyne. Petrópolis: Vozes, 2011.

WINCH, Christopher. GINGELL, John. Dicionário de filosofia da educação. Tradução de Renato Marques de Oliveira. São Paulo: Contexto, 2015.

\section{Como referenciar este artigo}

MESSIAS, Elvis Rezende.; MARIANO, André Luiz Sena. A docência ontem e hoje entre o ser amado e o ser temido: a questão da autoridade. Revista Ibero-Americana de Estudos em Educação, Araraquara/SP, v. 12, n. 2, p. 815-831, 2017. Disponível em: <http://dx.doi.org/10.21723/riaee.v12.n2.8390>. E-ISSN: 1982-5587.

Recebido em: 28/02/2016

Aprovação final em: 16/03/2017 